\title{
PERBANDINGAN UNJUK KERJA SISTEM PENDINGIN DENGAN OUTDOOR 1 PK DAN 0,5 PK
}

\author{
Farid Nurdiansyah \\ Teknik Mesin, Fakultas Teknik \\ Universitas Maarif Hasyim Latif, Sidoarjo, Indonesia \\ e-mail :farid-nurdiansyah@student.umaha.ac.id, penulis2@kedua.com
}

\begin{abstract}
ABSTRAK
Penelitian ini di gunakan untuk mengetahui bagaimana pengaruh perbandingan Outdoor AC untuk penentukan unjuk kerja mesin pendingin. Dalam hal ini pendingin untuk perkantoran dan rumah tangga. Untuk mencapai tujuan tersebut, di lakukan langkah langkah kerja sebagai berikut: pertama melakukan penelitian, kemudian menggambil data, setelah itu data di olah dan di masukkan kedalam tabel untuk menggetahui unjuk kerja perbandingan Outdoor AC tersebut. Pada proses penggantian Outdoor dari awal sampai akhir berjalan dengan lancar dan tidak ada kerusakan pada unit Outdoor. Semakit banyak refrigerant maka semakin besar amper yang di hasilkan, begitu pula dengan semakit kurang refrigerant maka akan semakit AC itu tidak dingin dan bila di biarkan akan mempengarhi kinerja kompresor AC. Dengan hasil perbandingan di atas cop AC 1 PK sebesar 7,5 dan cop AC 0,5 PK sebesar 12,86
\end{abstract}

Kata kunci: Air Conditioner, cop, kompresor, outdoor, refregeran

\section{PENDAHULUAN}

Manusia selalu membutuhkan udara yang nyaman. Peningkatan penggunaan AC dapan meningkatkan konsumsi listrik. Melihat pernyataan tersebut, banyak peneliti melakukan riset untuk menekan penggunaan listrik dengan cara penggantian outdoor pada AC.

Oleh karena itu pada penelitian ini dilakukan eksperimen pada perangkat AC Split dengan merk Midea 1PK dan AC LG 0,5 PK Penelitian ini bertujuan untuk analisa pengaruh variasi pengaruh daya kompresor terhadap unjuk kerja AC Split PK.

Oleh karena itu pada penelitian ini dilakukan eksperimen pada perangkat AC Split dengan merk Midea 1PK dan AC LG 0,5 PK Penelitian ini bertujuan untuk analisa pengaruh variasi pengaruh daya kompresor terhadap unjuk kerja AC Split PK.

Kelemahan refrigeran sintetik muncul setelah penggunaan yang lama, efek negatif dari refrigeran sintetik terutama yang mengandung senyawa CFC: R-12 dan R-22 terhadap lingkungan adalah menjadi penyebab rusaknya lapisan ozon (Ozone Depleting Potensial/ ODP) serta memiliki potensi pemanasan global (Global Warming Potential/ GWP). Di Indonesia, pemerintah sudah menghentikan impor CFC (freon; R-12 untuk dan R22 untuk air conditioning) pada akhir 2007 serta menganjurkan penggunaan refrigeran hidrokarbon. Salah satu refrigeran alternatif pengganti R-22 di Indonesia adalah (MussiCool-22) MC-22 yang merupakan refrigeran hydrokarbon produksi pertamina. Rerfrigeran hidrokarbon sangat flammable, terjadi secara alami, memiliki potensi nol penipisan ozon dan penyebab pemanasan global yang dapat diabaikan. Secara teori, hidrokarbon sangat potensial sebagai refrigeran namun memiliki sifat sangat mudah terbakar.

\section{METODE PENELITIAN}

\section{Diagram Alir}

Metode yang digunakan dalam penelitian ini adalah metode eksperimen dengan didukung literatureliteratur yang terkait. Urutan kerja penelitian ini dapat dilihat pada diagram alir prosedur penelitian dibawah ini:

\section{Penjelasan Diagram Alir}

Dalam pelaksanaan Tugas akhir ini melalui beberapa prosedur pengujian sebagai berikut:

1. Mulai.

Mencari ide penelitian yang sesuai bidang minat

2. Referensi

Mencari sumber-sumber penelitian sebelumnya

3. Studi laporan

Perencanaan penelitian ini berdasarkan laporan yang mempunyai relevansi dengan permasalahan yang akan dihadapi, baik buku teks, jurnal, penelitian dan lain-lain.

4. Persiapan alat dan bahan Dalam tahap ini adalah menyiapkan apa saja yang dibutuhkan dalam penilitian ini.

5. Percobaan unjuk kerja AC 1 pk Menguji unjuk kerja ac 1 pk dengan unit indoor $1 \mathrm{pk}$.

6. Penggantian outdoor AC 
Penggantian outdoor dari yang sebelumnya 1 pk dengan cara melepas pipa dan kabel listrik kemudian memasang kembali dengan outdoor 1 pk dan memasang juga kabel dan saliran pipanya

7. Percobaan unjuk kerja AC $0,5 \mathrm{pk}$

Mencoba dan menguji unjuk kerja AC 0,5 pk

8. Analisis dan perhitungan

9. Ya atau Tidak

Bila percobaan berhasil kemudian melanutkan ke tahap pembuatan laporan dan jika Tidak mengulang kembali pengujian Percobaan unjuk kerja outdoor 1 pk dan selanjutnya.

10. Laporan

Bentuk penyampaian berita, keterangan, pemberitahuan ataupun pertanggungjawaban baik secara lisan maupun secara tertulis.

11. Kesimpulan

Sebuah gagasan yang tercapai pada akhir pembicaraan.

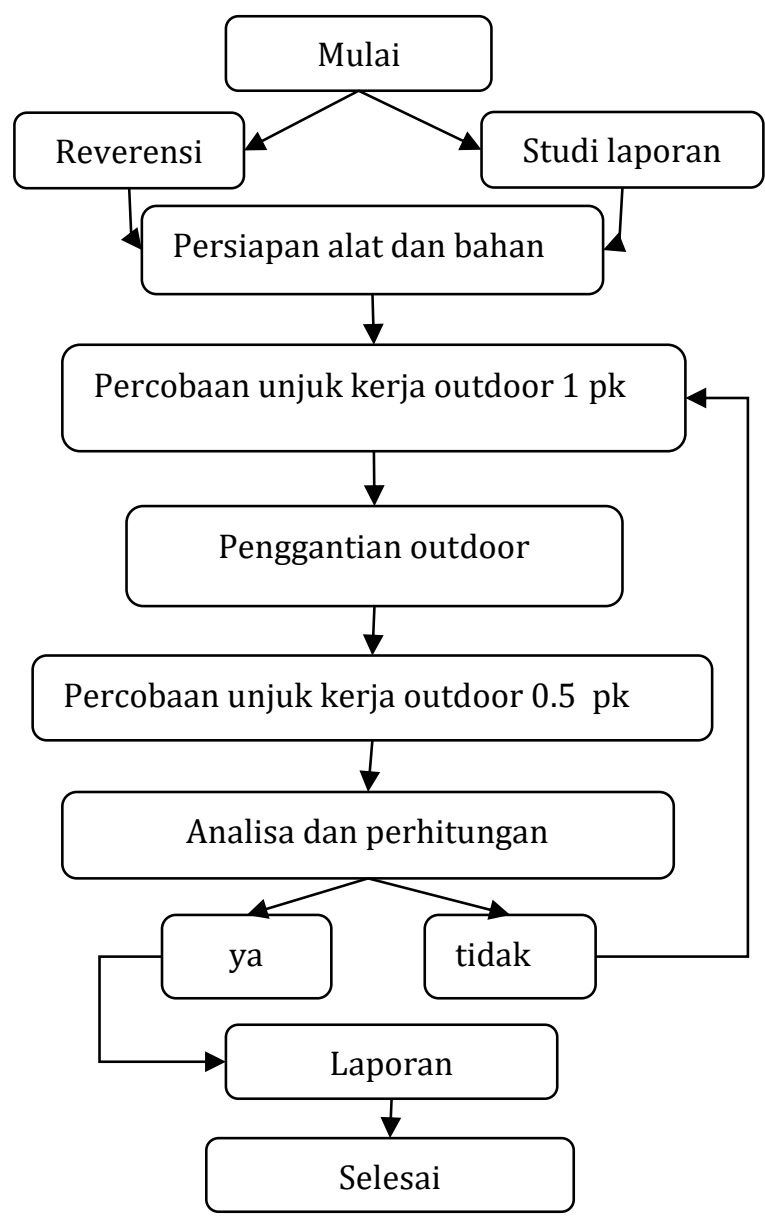

Gambar 1. Diagram alir penelitian

\section{HASIL DAN PEMBAHASAN}

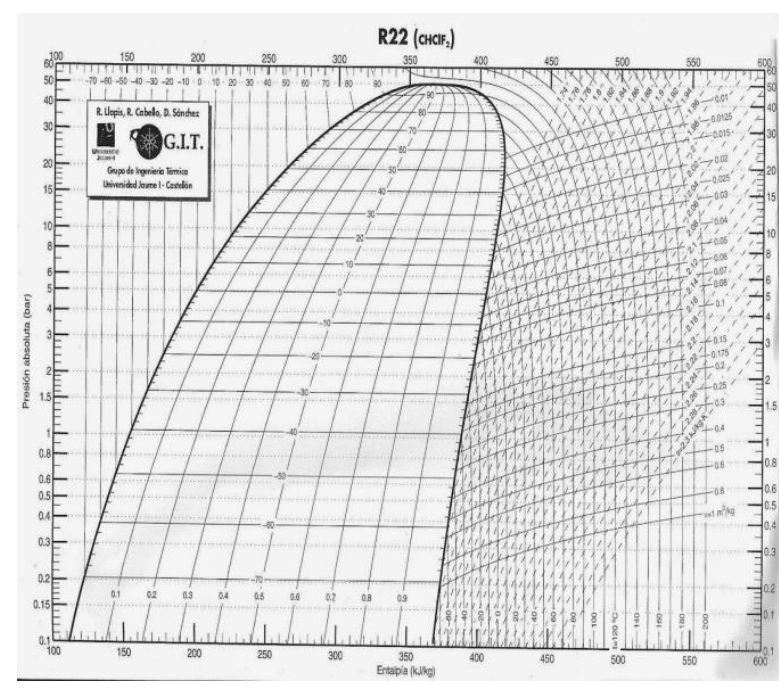

Tabel 4.1 Kapasitas AC 1 PK

\begin{tabular}{|c|c|}
\hline \multicolumn{2}{|c|}{ Unit outdoor 1 PK dengan indoor 1 PK } \\
\hline Capacity & $1 \mathrm{PK}$ \\
\hline BTU & $9000 \mathrm{BTU} / \mathrm{h}$ \\
\hline Refrigerant Volume & $\mathrm{R}-22$ \\
\hline Rated Frequency & $50 \mathrm{hz}$ \\
\hline Rated Voltage & $220 \mathrm{Volt}$ \\
\hline Rated Current & $3.2 \mathrm{Ampere}$ \\
\hline Rate Input & $690 \mathrm{Watt}$ \\
\hline Coverage Floor Area & $10-17 \mathrm{~m}^{2}$ \\
\hline
\end{tabular}

Tabel 4.1 Kapasitas AC 1 PK

\begin{tabular}{|c|c|}
\hline Temperatur Udara & $18{ }^{\circ} \mathrm{C}$ \\
\hline $\mathrm{P}_{1}($ Bar $)$ & 1,7 \\
\hline $\mathrm{T}_{1}\left({ }^{\circ} \mathrm{C}\right)$ & 27 \\
\hline $\mathrm{P}_{2}($ Bar $)$ & 12,13 \\
\hline $\mathrm{T}_{2}\left({ }^{\circ} \mathrm{C}\right)$ & 58,5 \\
\hline $\mathrm{P}_{3}(\mathrm{Bar})$ & 11,4 \\
\hline $\mathrm{T}_{3}\left({ }^{\circ} \mathrm{C}\right)$ & 27,2 \\
\hline
\end{tabular}

Keadaan titik 1

$\mathrm{P}_{1}=1.7 \mathrm{bar}$ 
$\mathrm{T}_{1}=27^{\circ} \mathrm{C}$

Dilihat dari tabel, maka titik jenuh P1 = 1,7 bar adalah $-29^{\prime} \mathrm{C}$, karena pada analisa data temperatur adalah 27 'c, maka kejadian ini bisa terpengaruhi oleh panas sekitar AC tersebut. Maka dibuatkan range antara 27'C dan-29'C untuk mendapatkan $\mathrm{H} 1$ sebagai berikut. $\mathrm{H}_{1}$ diketahui melalui hasil range antara $27^{\prime} \mathrm{C}$ dan $-29^{\prime} \mathrm{C}$ yaitu 408kj/kg

Keadaan titik 2

$\mathrm{P}_{2}=12,13$ bar $=1213 \mathrm{kpa}$

$\mathrm{T}_{2}=58,5^{\circ} \mathrm{C}$

Jika dilihat pada table A-11 maka titik jenuh pada $\mathrm{P}_{2}=12,13 \mathrm{Bar}=1213 \mathrm{kPa}$ adalah $30,5^{\circ} \mathrm{C}$. Dari grafik maka diperoleh $\mathrm{h}_{2}=433 \mathrm{~kJ} / \mathrm{kg}$

Keadaan titik 3

$\mathrm{P}_{3}=11,4$ bar $=1140 \mathrm{kpa}$

$\mathrm{T}_{3}=27,2^{\prime} \mathrm{c}$

Jika dilihat pada table A-11 maka titik jenuh pada $\mathrm{P}_{3}=11,4 \mathrm{Bar}=1140 \mathrm{kpa}$ adalah $28,5^{\circ} \mathrm{C}$. Dari grafik maka diperoleh $\mathrm{h}_{3}=223 \mathrm{~kJ} / \mathrm{kg}$

\section{Keadaan titik 4}

Keadaan ini terjadi pada pipa kapiler yang tidak versible maka

$\mathrm{h}_{4}=\mathrm{h}_{3}=223 \mathrm{~kJ} / \mathrm{kg}$

Efek refrijerasi :

$\mathrm{H}_{1}-\mathrm{H}_{4}=408 \mathrm{kj} / \mathrm{kg}-223 \mathrm{kj} / \mathrm{kg}=185 \mathrm{kj} / \mathrm{kg}$

Laju Aliran Massa Refrigerant : Kapasitas refrijerasi dibagi efek refrigerasi

$\mathrm{Wc}=\dot{m}\left(\mathrm{~h}_{2}-\mathrm{h}_{1}\right)$

$\dot{m}=\frac{W c}{h_{2}-h_{1}}=\frac{746 \text { watt }}{433 \frac{\mathrm{kj}}{\mathrm{kg}}-408 \frac{\mathrm{kj}}{\mathrm{kg}}}=\frac{0.746 \frac{\mathrm{kj}}{\mathrm{s}}}{25 \frac{\mathrm{kj}}{\mathrm{kg}}}$

$=\frac{0.746 \frac{\mathrm{kj}}{\mathrm{s}}}{25 \frac{\mathrm{kj}}{\mathrm{kg}}}=0.02984 \frac{\mathrm{kg}}{\mathrm{s}}$

$\mathrm{Qc}=\dot{m}\left(\mathrm{~h}_{2}-\mathrm{h}_{3}\right)$

$=0.02984 \frac{\mathrm{kg}}{\mathrm{s}}(433 \mathrm{kj} / \mathrm{kg}-223 \mathrm{kj} / \mathrm{kg})$

$=0.02984 \frac{\mathrm{kg}}{\mathrm{s}}\left(210 \frac{\mathrm{kj}}{\mathrm{kg}}\right)=6.2664 \frac{\mathrm{kj}}{\mathrm{s}}$

$\mathrm{Qe}=\dot{m}\left(\mathrm{~h}_{1}-\mathrm{h}_{4}\right)$

$=0.02984 \frac{\mathrm{kg}}{\mathrm{s}}(408 \mathrm{kj} / \mathrm{kg}-223 \mathrm{kj} / \mathrm{kg})$

$=0.02984 \frac{\mathrm{kg}}{\mathrm{s}}\left(185 \frac{\mathrm{kj}}{\mathrm{kg}}\right)=5.5204 \frac{\mathrm{kj}}{\mathrm{s}}$

$\mathrm{COP}=\frac{h 1-h 4}{h 2-h 1}=\frac{408 \frac{\mathrm{kj}}{\mathrm{kg}}-223 \frac{\mathrm{kg}}{\mathrm{kj}}}{433 \frac{\mathrm{kj}}{\mathrm{kg}}-408 \frac{\mathrm{kj}}{\mathrm{kg}}}=\frac{185}{25}=7.5$

4 Perhitungan Unjuk Kerja Dengan Menggunakan Outdoor 0,5 PK

Pada sub-bab ini akan dihitung hasil analisa dari pengambilan data sama seperti pada data 4.1 akan tetapi pada kali ini saya menggunakan Outdoor 0.5 PK. Dengan hasil yang saya dapat sebagai berikut:

Tabel 4.3 kapasitas AC 0.5 PK

\begin{tabular}{|c|c|}
\hline \multicolumn{2}{|c|}{ Unit outdoor 0,5 PK dengan indoor 1 PK } \\
\hline Capacity & $0,5 \mathrm{PK}$ \\
\hline BTU & $5000 \mathrm{BTU} / \mathrm{h}$ \\
\hline Refrigerant Volume & $\mathrm{R}-22$ \\
\hline Rated Frequency & $50 \mathrm{hz}$ \\
\hline Rated Voltage & $220 \mathrm{Volt}$ \\
\hline Rated Current & $1,5 \mathrm{Ampere}$ \\
\hline Rate Input & $400 \mathrm{Watt}$ \\
\hline Coverage Floor Area & $10-17 \mathrm{~m}^{2}$ \\
\hline
\end{tabular}

Tabel 4.1 Kapasitas AC 1 PK

\begin{tabular}{|c|c|}
\hline Temperatur Udara & $18^{\circ} \mathrm{C}$ \\
\hline $\mathrm{P}_{1}(\mathrm{Bar})$ & 1,5 \\
\hline $\mathrm{T}_{1}\left({ }^{0} \mathrm{C}\right)$ & 27 \\
\hline $\mathrm{P}_{2}(\mathrm{Bar})$ & 12,10 \\
\hline $\mathrm{T}_{2}\left({ }^{\circ} \mathrm{C}\right)$ & 50,5 \\
\hline $\mathrm{P}_{3}(\mathrm{Bar})$ & 10,4 \\
\hline $\mathrm{T}_{3}\left({ }^{\circ} \mathrm{C}\right)$ & 16,2 \\
\hline
\end{tabular}

a. Keadaan titik 1

$$
\begin{aligned}
& \mathrm{P}_{1}=1.5 \mathrm{bar} \\
& \mathrm{T}_{1}=27^{0} \mathrm{c}
\end{aligned}
$$

Dilihat dari tabel, maka titik jenuh $\mathrm{P}_{1}=1,5 \mathrm{bar}$ adalah $-30{ }^{\circ} \mathrm{C}$, karena pada analisa data temperatur adalah $27{ }^{0} \mathrm{C}$, maka kejadian ini bisa terpengaruhi oleh panas sekitar AC tersebut. Maka dibuatkan range antara $27^{\circ} \mathrm{C}$ dan $-29^{\circ} \mathrm{C}$ untuk mendapatkan $\mathrm{H}_{1}$ sebagai berikut. $\mathrm{H}_{1}$ diketahui melalui hasil range antara $27^{\circ} \mathrm{C}$ dan $-29^{\circ} \mathrm{C}$ yaitu $368 \mathrm{kj} / \mathrm{kg}$.

Keadaan titik 2

$\mathrm{P}_{2}=12,10$ bar $=1150 \mathrm{kpa}$

$\mathrm{T}_{2}=50,5^{\circ} \mathrm{C}$

maka titik jenuh pada $\mathrm{P} 2=12,10 \mathrm{Bar}=1150 \mathrm{kPa}$ adalah 30,5 ${ }^{\circ}$ C.Maka diperoleh $\mathrm{h}_{2}=430 \mathrm{~kJ} / \mathrm{kg}$

Keadaan titik 3

$\mathrm{P}_{3}=10,4$ bar $=1040 \mathrm{kpa}$

$\mathrm{T}_{3}=26,2^{\circ} \mathrm{c}$

Maka titik jenuh pada $\mathrm{P}_{3}=10,4 \mathrm{Bar}=1040 \mathrm{kpa}$ adalah $28,5^{\circ} \mathrm{C}$. Dari grafik pada lampiran maka diperoleh $\mathrm{h}_{3}=145 \mathrm{~kJ} / \mathrm{kg}$

Keadaan titik 4

Keadaan ini terjadi pada pipa kapiler yang tidak versible maka 
$\mathrm{h}_{4}=\mathrm{h}_{3}=145 \mathrm{~kJ} / \mathrm{kg}$

Efek refrijerasi :

$\mathrm{H}_{1}-\mathrm{H}_{4}=368 \mathrm{kj} / \mathrm{kg}-145 \mathrm{kj} / \mathrm{kg}=223 \mathrm{kj} / \mathrm{kg}$

Laju Aliran Massa Refrigerant : Kapasitas refrijerasi dibagi efek refrijerasi

$\mathrm{Wc}=\dot{m}\left(\mathrm{~h}_{2}-\mathrm{h}_{1}\right)$

$\dot{m}=\frac{W c}{h_{2}-h_{1}}=\frac{400 w a t t}{430 \frac{\mathrm{kj}}{\mathrm{kg}}-368 \frac{\mathrm{kj}}{\mathrm{kg}}}=\frac{0.400 \frac{\mathrm{kj}}{\mathrm{s}}}{430 \frac{\mathrm{kj}}{\mathrm{kg}}-368 \frac{\mathrm{kj}}{\mathrm{kg}}}$

$=\frac{0.400 \frac{\mathrm{kj}}{\mathrm{s}}}{62 \frac{\mathrm{kj}}{\mathrm{kg}}}=0.0064 \frac{\mathrm{kg}}{\mathrm{s}}$

$\mathrm{Qc}=\dot{m}\left(\mathrm{~h}_{2}-\mathrm{h}_{3}\right)$

$=0.0064 \frac{\mathrm{kg}}{\mathrm{s}}(430 \mathrm{kj} / \mathrm{kg}-145 \mathrm{kj} / \mathrm{kg})$

$=0.0064 \frac{\mathrm{kg}}{\mathrm{s}}\left(258 \frac{\mathrm{kj}}{\mathrm{kg}}\right)=4.69044 \frac{\mathrm{kj}}{\mathrm{s}}$

$\mathrm{Qe}=\dot{m}\left(\mathrm{~h}_{1}-\mathrm{h}_{4}\right)$

$=0.0064 \frac{\mathrm{kg}}{\mathrm{s}}(368 \mathrm{kj} / \mathrm{kg}-145 \mathrm{kj} / \mathrm{kg})$

$=0.0064 \frac{\mathrm{kg}}{\mathrm{s}}\left(223 \frac{\mathrm{kj}}{\mathrm{kg}}\right)=1.4272 \frac{\mathrm{kj}}{\mathrm{s}}$

$\mathrm{COP}=\frac{h 1-h 4}{h 2-h 1}=\frac{368 \frac{\mathrm{kj}}{\mathrm{kg}}-145 \frac{\mathrm{kg}}{\mathrm{kj}}}{430 \frac{\mathrm{kj}}{\mathrm{kg}}-368 \frac{\mathrm{kj}}{\mathrm{kg}}}=\frac{223}{62}=3,59$

Tabel 4.5 Hasil Perbandingan Kinerja Outdoor

\begin{tabular}{|c|c|c|c|}
\hline Outdoor & QE & QC & COP \\
\hline 1 PK & $5.5204 \frac{\mathrm{kj}}{\mathrm{s}}$ & $6.2664 \frac{\mathrm{kj}}{\mathrm{s}}$ & 7,5 \\
\hline $0,5 \mathrm{PK}$ & $1.4272 \frac{\mathrm{kj}}{\mathrm{s}}$ & $4.69044 \frac{\mathrm{kj}}{\mathrm{s}}$ & 3,59 \\
\hline
\end{tabular}

Tabel 4.6 Hasil Perbandingan Waktu dan Temperatur

\begin{tabular}{|c|c|c|c|}
\hline Outdoor & $\begin{array}{c}\text { Temperatur } \\
\text { Evaporator }\end{array}$ & $\begin{array}{c}\text { Temperatur } \\
\text { Kondensator }\end{array}$ & Waktu \\
\hline $1 \mathrm{PK}$ & $18^{\circ} \mathrm{C}$ & $72^{\circ} \mathrm{C}$ & $\begin{array}{c}55 \\
\text { menit }\end{array}$ \\
\hline $0,5 \mathrm{PK}$ & $22^{\circ} \mathrm{C}$ & $58^{\circ} \mathrm{C}$ & $\begin{array}{c}75 \\
\text { menit }\end{array}$ \\
\hline
\end{tabular}

\section{PENUTUP}

Pada proses penggantian Outdoor dari awal sampai akhir berjalan dengan lancar dan tidak ada kerusakan pada unit Outdoor.

Semakit banyak refrigerant maka semakin besar amper yang di hasilkan, begitu pula dengan semakit kurang refrigerant maka akan semakit $\mathrm{AC}$ itu tidak dingin dan bila di biarkan akan mempengarhi kinerja kompresor AC.

Dengan hasil perbandingan di atas cop AC 1 PK sebesar 7,5 dan cop AC 0,5 PK sebesar 12,86

\section{DAFTAR PUSTAKA}

Afifah, Y. N. (2016). Aliran Tak Tunak Fluida Nano Magnetohidrodinamik (MHD) Yang Melewati Bola Teriris.

Afifah, Y. N. (2019). (2019). Analysis of Unsteady Magneto Hydro Dynamic ( MHD ) Nano Fluid Flow Past A Sliced Sphere Analysis of Unsteady Magneto Hydro Dynamic ( MHD ) Nano Fluid Flow Past A Sliced Sphere. IOP Conference Series: Materials Science and Engineering, $\quad 494, \quad 012033$. https://doi.org/10.1088/1757899X/494/1/012033

Dwi Basuki Wibowo dan Mohammad Subri, 2006, Pengaruh Variasi Massa Refrigeran R-22 dan Putaran Blower Evaporator terhadap COP Pada Sistem Pengkondisian Udara Mobil.

Dossan J., roy. 1990. Principles Of Refrigeration S1 Version. Edisi pertama. Penerbit Universitas Of Houston. Texas.

Khoiruddin, M., \& Ardinanta, F. (2018). RANCANG BANGUN ALAT PERAGA MESIN PENDINGIN AC SPLIT $3 / 4$ PK. 1, 1-6.

Michael J., Maron dan Howard N., Shapiro. 2004. Thermodinamika Teknik Jilid I. Edisi keempat. Terjemahan Yulianto

Reynolds, Wilbert F. dan W. Jones, Jerold. 1991. Thermodinamika Teknik. Edisi kedua. Terjemahan Filipno Harahap. Penerbit Erlangga. Jakarta.

Stoecker, W.F. dan Jerold, W. J., 1996, Refrigerasi dan Penyegaran Udara. Terjemahan Supratman Hara. Penerbit Erlangga. Jakarta.

Yunita Nur Afifah, MNH Qomarudin, \& Imamatul Ummah. (2020). Optimal Control Model Pemanenan Prey-Predator di Area Konservasi Ikan. Buana Matematika: Jurnal Ilmiah Matematika Dan Pendidikan Matematika, 10(1), 1-16. https://doi.org/10.36456/buanamatematik a.v10i1.2410 